\title{
Deciding Factors for the Referral \\ of a Female Patient to a Specific Hospital from the Viewpoint of Practice-Based Specialists
}

\author{
Ausschlaggebende Faktoren für die Zuweisung einer Patientin \\ in eine bestimmte Klinik aus Sicht niedergelassener Fachärzte
}

Authors

Affiliations
S. Baum ${ }^{1}$, G. Meyberg-Solomayer ${ }^{1}$, A. Baum ${ }^{2}$, J. Radosa ${ }^{1}$, A. Hamza ${ }^{1}$, B. Gronwald ${ }^{3}$, M. Friedrich ${ }^{4}$, E. F. Solomayer ${ }^{1}$, R. Joukhadar ${ }^{1}$

The affiliations are listed at the end of the article.

\author{
Key words \\ - practice-based specialists \\ - factors for referral \\ - patients \\ - hospitals \\ - cooperation \\ Schlüsselwörter \\ - niedergelassene Fachärzte \\ - Zuweisungsfaktoren \\ - Patienten \\ - Krankenhaus \\ - Kooperation
}

Deutschsprachige Zusatzinformationen online abrufbar unter: www.thieme-connect.de/ ejournals/toc/gebfra

\section{received 9.9.2014 revised $\quad 17.3 .2015$ accepted $\quad 6.4 .2015$}

Bibliography

DOI http://dx.doi.org/

10.1055/s-0035-1546035

Geburtsh Frauenheilk 2015; 75 :

456-461 @ Georg Thieme

Verlag KG Stuttgart · New York . ISSN 0016-5751

\section{Correspondence}

Dr. Sascha Baum

Universitätsklinikum

des Saarlandes

Klinik für Frauenheilkunde,

Geburtshilfe und

Reproduktionsmedizin

Kirrberger Straße 100

66424 Homburg

sascha.baum@uks.eu

\section{Abstract \\ V}

Background: One of the key points of patient care is the cooperation between practice-based specialists and clinical facilities. The present study was undertaken in order to illustrate the deciding factors, from the viewpoint of practice-based specialists, for the referral of a female patient to a specific hospital.

Methods: Altogether a total of 322 practice-based specialists from various disciplines were contacted in writing and sent a questionnaire. In this survey the recipients were questioned about the criteria, in order of importance, applied for the referral of a (female) patient to a specific clinical facility.

Results: In the foreground for the referral of a patient to a specific hospital are the aspects of medical quality and competence. On a closer look we find the surgical spectrum, especially the availability of endoscopic and special operations as a main factor. Further factors are a low rate of complications and the availability of modern diagnostic methods. Also evaluated as an important aspect was the easy reachability of a competent consultant. Factors of lower relevance for referral behaviour were personal familiarity with the colleagues employed in the hospital, specific further training events and the course of previous cooperation.

Conclusions: A modern diagnostic and therapeutic spectrum coupled with an easy reachability of competent contact partners are the main factors for cooperation from the viewpoint of the practice-based specialist. Of lowest relevance, among others, was the aspect of previous cooperation. Thus, it can be seen that by means of changes in cooperation an improvement in patient care can be achieved at any time.

\section{Zusammenfassung \\ $\nabla$}

Hintergrund: Eine der Schlüsselstellen in der Patientinnenversorgung ist die Zusammenarbeit zwischen niedergelassenen Fachärzten und klinischen Einrichtungen. Diese Untersuchung wurde durchgeführt, um die ausschlaggebenden Faktoren aus Sicht niedergelassener Fachärzte für die Zuweisung einer Patientin in eine bestimmte Klinik darzustellen.

Methoden: Es wurden insges. 322 niedergelassene Fachärzte verschiedener Disziplinen mittels Fragebogen angeschrieben. In diesem Anschreiben wurden die Kriterien bez. ihrer Wichtigkeit für die Zuweisung einer Patientin in eine bestimmte klinische Einrichtung abgefragt.

Ergebnisse: Im Vordergrund für die Zuweisung einer Patientin in eine bestimmte Klinik stehen die Aspekte der medizinischen Qualität und Kompetenz. Näher spezifiziert zeigte sich hier das operative Spektrum, besonders das Angebot endoskopischer und spezieller Operationen als Hauptpunkte. Weitere Faktoren waren eine niedrige Komplikationsrate und das Angebot moderner Diagnoseverfahren. Ebenfalls als wichtiger Punkt gewertet wurde die gute Erreichbarkeit eines kompetenten Ansprechpartners. Faktoren von geringster Relevanz für das Zuweisungsverhalten waren die persönliche Bekanntheit mit den in der Klinik tätigen Kollegen, spezifische Fortbildungsveranstaltungen und der Verlauf der bisherigen Zusammenarbeit.

Schlussfolgerungen: Ein modernes Diagnostikund Therapiespektrum gepaart mit einer guten Erreichbarkeit eines kompetenten Ansprechpartners sind aus Sicht niedergelassener Fachärzte die Hauptfaktoren für die Zusammenarbeit. Von geringster Relevanz stellte sich unter anderem der Punkt der bisherigen Zusammenarbeit dar. Daraus zeigt sich, dass durch Änderung in der Kooperation jederzeit eine Verbesserung der Patientinnenversorgung erzielt werden kann. 


\section{Introduction}

\section{$\nabla$}

The objective of practice-based specialists as well as of physicians working in hospitals is to provide the optimal care for their patients. In order to achieve this, a loss-free management of the patient between the practice-based specialist and physicians working in hospitals is of major importance.

The prominent position of a continuous treatment chain between outpatient and inpatient care was also pointed out by Spießl et al. [1]. This functional dovetailing of cooperating partners is therefore of the greatest importance to avoid multiple treatments and to ensure the continuity of care. A functioning dovetailing between outpatient and inpatient care of patients is not only of exceptional significance in gynaecology but is also in other disciplines a major factor of cooperation that must be guaranteed [2]. Thus it is necessary not only for those working in outpatient care but also for those in hospitals to be mutually informed about diagnostic findings, performed interventions and planned further measures in good time. By means of this flow of information, better quality for and treatment of the patient can be safely achieved.

Thus it is clear that a functioning bidirectional communication between the treating partners can be considered as one of the most important aspects for a good and successful cooperation. The importance of communication has also been emphasised by other authors [3-6].

From the viewpoint of clinical facilities, it is still of great interest as to which other factors, beside communication, are deciding for the referral behaviour of practice-based specialists. This interest about the factors that lead to the referral of a patient to a specific hospital is based not least on the interest of the hospital to fulfil just this profile as well as possible. Because of the increasing economic pressure on hospitals, the referral behaviour of practicebased specialists is gaining in importance.

Various factors can be found in the literature that influence patient referral behaviour by practice-based specialists. These points depend, among others, on the patient's current problem, the personal attitude, the diagnostic competence and the availability of own resources by the referring physician $[5,7,8]$.

Up to now there are only a limited number of reports, not only in the German speaking countries but also international, that deal with the cooperation between practice-based specialists and clinical facilities. The aim of the present study is to determine which factors the practice-based specialist considers to be decisive for the referral of a female patient to a specific hospital.

On the basis of the collected data, we present an attempt to improve the cooperation between hospitals and practice-based specialists by illustrating just those points that have as yet not appropriately been considered by the hospitals but which the external colleagues believe to be important.

A further aspect of our investigation is whether or not there are significant differences in the evaluation of deciding factors for the referral of a patient to a specific hospital among the individual groups of practice-based specialists.

\section{Materials and Methods}

\section{Modalities of the survey}

In order to determine these criteria we approached over a period of 6 months a total of 322 specialists from various disciplines. The approached colleagues were all practice-based specialists who had during the past 3 years admitted or referred at least one patient to our hospital.

We sent the practice-based colleagues a one-page questionnaire containing questions in 4 main categories. Thus, the questionnaire consisted of a total of 19 questions which could be answered with a score of 1 to 6 whereby 1 means very important and 6 not important.

Furthermore, as a last item, the possibility to add free comments, was available on the questionnaire.

\section{Structure of the questionnaire}

The 4 main categories consisted of the following aspects:

- medical aspects

- patient-related aspects

- contact opportunities

public recognition

\section{Possibilities for answering the questionnaire}

A stamped and addressed reply envelope accompanied the initial letter. It was also possible to return the completed form by fax. As a 3rd option an online question portal was established for the questions and the specialists were given the access code in the initial letter.

For the assessment and evaluation of the importance of the individual questions from the viewpoint of approached colleagues, an average value was determined from the frequency of the individual answers. Furthermore, we also checked which points were considered to be very important and thus scored as 1 by the participants or, respectively, as not at all important and scored as 6 .

Thus it can be recognised that the lower the average value for each individual question the more important is this criterion for the referral of a patient.

\section{Statistical evaluation}

The statistical analyses in this investigation were carried out with the help of the software SPSS Statistics 19 from IBM. For each and every question, a mean value and standard deviation are given. The t-test was used to check for significant differences between the 2 main referring groups.

\section{Results}

$\nabla$

Description of the surveyed collective

For this study specialists for 10 different disciplines were approached. The different specialist fields are:

gynaecology and obstetrics, general medicine, orology, radiology/nuclear medicine, surgery, internal medicine, dermatology, otorhinolaryngology, paediatrics and orthopaedics. Some of the approached colleagues were specialists for both internal medicine and general medicine. The distribution among the various specialties is listed in 0 Table 1.

The number of patients referred by the individual specialists ranged from 1 up to 159 in a calendar year. On average 5.75 patients per specialist per year were referred to our hospital. Among the specialists with the highest numbers of referrals, the first 28 places were occupied by gynaecologists. Only at the 29 th place did the first referring member from another discipline, general medicine, appear.

Altogether, via all 3 reply routes, a response rate of $58.07 \%$, corresponding to 187 filled out questionnaires, was achieved. 
Table 1 Distribution of the participating practice-based specialists.

\begin{tabular}{|c|l|}
\hline Number & Specialty \\
\hline 161 & gynaecology \\
\hline 97 & general medicine \\
\hline 24 & internal medicine \\
\hline 10 & radiology \\
\hline 7 & urology \\
\hline 7 & general and internal medicine \\
\hline 3 & surgery \\
\hline 3 & paediatrics \\
\hline 3 & dermatology \\
\hline 1 & orthopaedics \\
\hline
\end{tabular}

As can be seen from - Fig. 1 the highest return rate was by fax with $43.31 \%$, followed by the post with $33.69 \%$. The lowest number of replies was received from the online portal with $23 \%$.

\section{Evaluation of the individual questions}

Of the 4 main categories, the medical aspects of a hospital provided the main reason for the practice-based specialists to refer a patient to a specific hospital. The second placed aspect was a good reachability, followed by patient-related aspects with almost identical ratings. Then following at some distance, the last place was occupied by the public recognition of a clinical facility or of an individual person or persons working therein ( $\bullet$ Fig. 2 ). The assessment of medical aspects as the deciding factor for the referral of a patient to a specific hospital could be demonstrated for all disciplines without exception.

Of the 6 points with the respective best average evaluations, 5 items were from the category medical aspects.

The question about the quality and competence of a hospital was found to be the most important referral criterion for a specific hospital. This is reflected in an average score of 1.25 ( $S D=0.45$ ). This question not only achieved the best average score but was also simultaneously considered as the most important evaluation criterion by most participants. Thus $77.14 \%$ of the surveyed colleagues assessed this point as very important (score =1) and further $20.95 \%$ as important (score $=2$ ). Altogether, a total of $98.09 \%$ of the participants in this survey considered this aspect to be the most important factor for a hospital. Accordingly, on the other hand, none of participants answered this question with a score of 4 or higher.

The importance of quality or, respectively, competence of a hospital was specified in more detail by the questions with the second and/or third best scores. It can be seen here which subareas are especially decisive for the referral of patients. The question about the surgical spectrum, as question with the second best score, reached an average value of $1.32(S D=0.47)$ and the question about the range of services or, respectively, therapeutic services offered with 1.36 ( $S D=0.48$ ) are of almost equal importance. Only 2 of the practice-based specialists rated the importance of the surgical spectrum with a score of 4 and none considered the surgical spectrum or, respectively, therapeutic services to be so unimportant to merit a score of 5 or 6 . While the offer of special operations was considered to be a very important factor, the frequency of performance of such special interventions was rated as being rather of secondary importance, resulting in

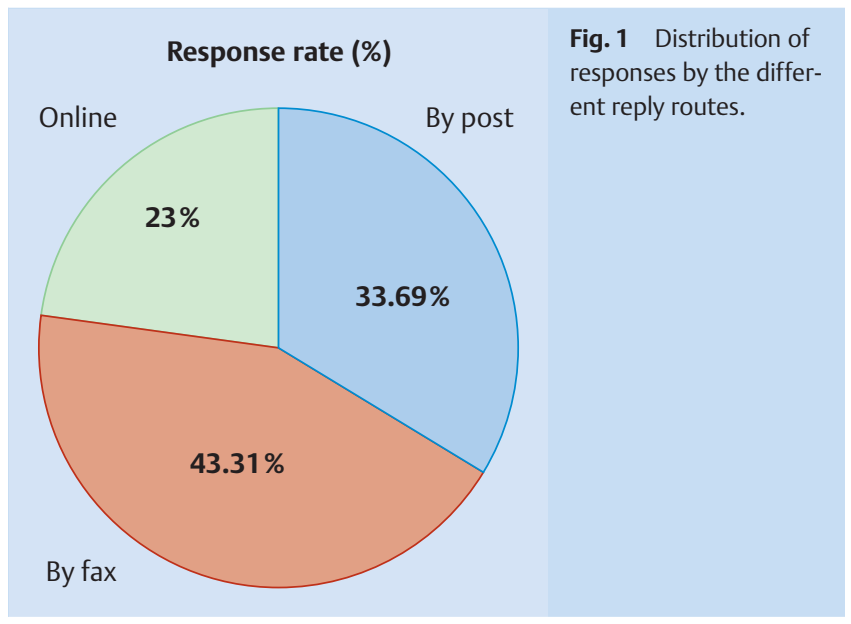

this aspect being in the last third with the 15th place (average value $1.94 ; \mathrm{SD}=1.35$ ).

If we add the free answer options from question 20 to these results, it can be seen that, apart from a low complication rate, also the availability of modern therapeutic and/or diagnostic methods as a quality feature also has a decisive influence. In the field of surgical therapy the performance of endoscopic interventions in contrast to open procedures was mentioned frequently.

As already stated above, there is one question among the 6 most important points that does not concern the medical aspects of a clinical facility. This is the item in position 4 concerning the reachability of a competent contact person (average score $=1.40$; $\mathrm{SD}=0.51$ ).

In comparison to the question with the 3rd highest score, the aspect of service spectrum or, respectively, therapies available, the possibility to easily reach a competent contact person was found to be very important by more participants and thus given the score 1 . This was 68.27 vs. $65.38 \%$, at the same time, $5.76 \%$ considered this to be less important and gave it a score of 3 or 4, in contrast only 2 specialists evaluated the therapy/services spectrum with the score 3 (=1.07\%).

On the evaluation of the importance of the various aspects of a gynaecological hospital, the subarea of surgical spectrum was the point with the second highest score. This was followed in rank 5 by the availability of prenatal diagnostics, a further special medical subfield (average score $=1.46 ; S D=0.54$ ). In the 6th place

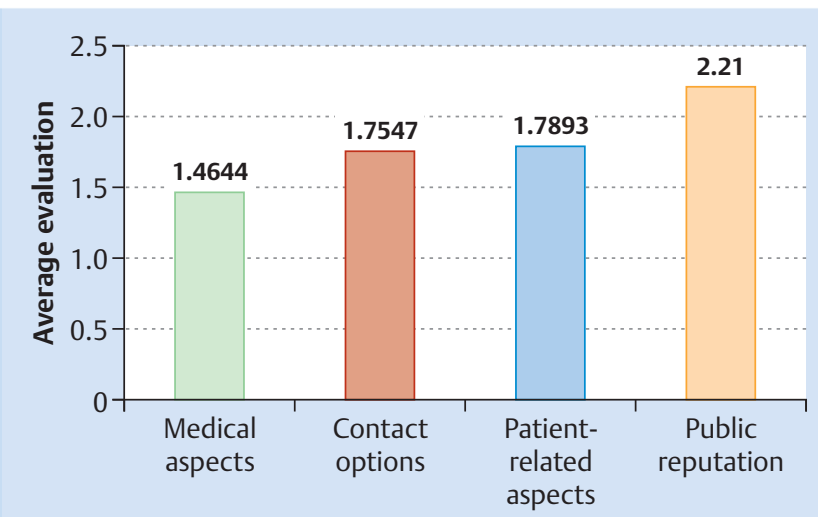

Fig. 2 Average evaluation of the investigated 4 main aspects. 


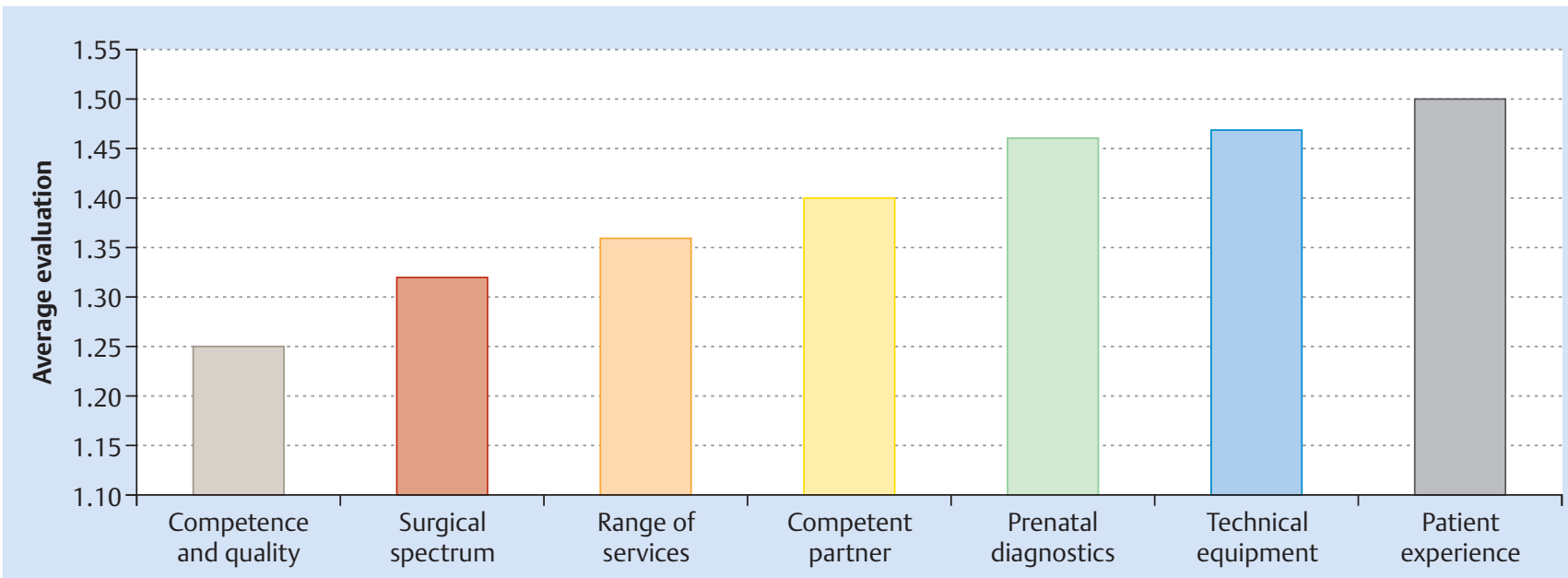

Fig. 3 Ranking of the 7 most important deciding factors for the referral of a patient to a specific gynaecological facility (the lower the average value the more important is the aspect for decision making).

came the medical-technical equipment of the hospital (average score $=1.47$; $\mathrm{SD}=0.58$ ).

Also, patient satisfaction or, respectively, the experience of the patients during the clinical care period is one of the most important points (average score $=1.50$; $\mathrm{SD}=0.57$, rank 7) for the decision to refer to a specific hospital. Overview in 8 Fig. 3.

As mentioned above, the opportunity for direct personal contact with a competent partner is scored with 1.4 ; in contrast, the general reachability of the hospital via a telephone hot line is evaluated with a score of $1.93(\mathrm{SD}=1.16)$. Expressed as a ranking order this means that the individual reachability occupies rank 4 whereas the general contact possibilities for the hospital occupies the 14th place among the total of 19 items. Communication, for example in the form of physicians' letters or other findings with a score of $1.6(\mathrm{SD}=0.74)$ takes up the 9th place.

Organisational features of a department such as standards of maintenance and care, dispatch of physicians' reports or fast assignment of appointments with short waiting times, having average scores of, respectively, $1.58(\mathrm{SD}=0.64)$ or 1.6 and 1.77 $(\mathrm{SD}=0.94)$ occur in the middle of the range with places 8 to 10 . Factors concerning the external image, such as the reputation of the hospital or its leaders, supporting contact by physicians employed by the hospital with the practice-based colleagues, appear near the bottom of the list at positions 11 and 12 (average scores for each 1.85 [SD = 1.07 or $S D=1.05]$ ).

The wish of the patient to attend a specific hospital follows in place 13 with an average score of $1.88(S D=1.1)$ and the regional proximity of the hospital takes up the third last position (place 17 , average score $=2.2$; $\mathrm{SD}=0.94$ ).

On the other hand, attendance of the hospital physicians in specific further training events or the personal acquaintance between the hospital physicians and their practice-based colleagues was the least important deciding factor for the referral of a patient (average score $=2.29$ or, respectively, 2.49; positions 18 and $19 ; \mathrm{SD}=0.96$ or $\mathrm{SD}=1.0$ ).

Position 16 was taken up by the question as to what role did the previous cooperation play as a criterion for referral, average score of $1.97(\mathrm{SD}=1.2)$ ( Table 2 ).

\section{Evaluation differences among the individual specialist groups}

In order to determine if there are significant differences in the evaluations between the individual groups of specialists, 5 questions each with the best or, respectively, the poorest evaluations from the two largest groups of referring specialists were compared. The two main groups were, on the one hand, the specialists for gynaecology and obstetrics and, on the other hand, the specialists for general medicine ( $\nabla$ Fig. 4). Altogether these two groups comprised 148 specialists, corresponding to $79.14 \%$ of all participants answering the questionnaire.

\section{Discussion}

In summary, it must be emphasised that for all referring specialists the medical competence of the hospital was the main reason for the choice. This is also supported by the fact that the range of services and therapy spectrum was considered to be the 3rd most important factor.

The item medical competence is further differentiated by the fact that the surgical spectrum or, respectively, the availability of prenatal diagnostics was considered to be very important. Furthermore, the technical equipment of a hospital also underlines the medical competence. The frequency with which particular operations are performed is, however, not one of the major factors. These factors all describe the range of available diagnostic or, respectively, therapeutic services and thus also the medical quality. For the last question as the only one for which free answers were possible, many participants mentioned the importance of a broad spectrum of endoscopic operations. This reflects the increasing significance of minimally invasive procedures in the surgical portfolio of a gynaecological hospital and thus also the role of laparoscopic surgery as one of the pillars of gynaecological surgery.

Following these medical quality factors are reachability and patient-related aspects. In this case the reachability of a competent partner for medical information is more important than the reachability via a hot line or the rapid dispatch of physicians' reports. 


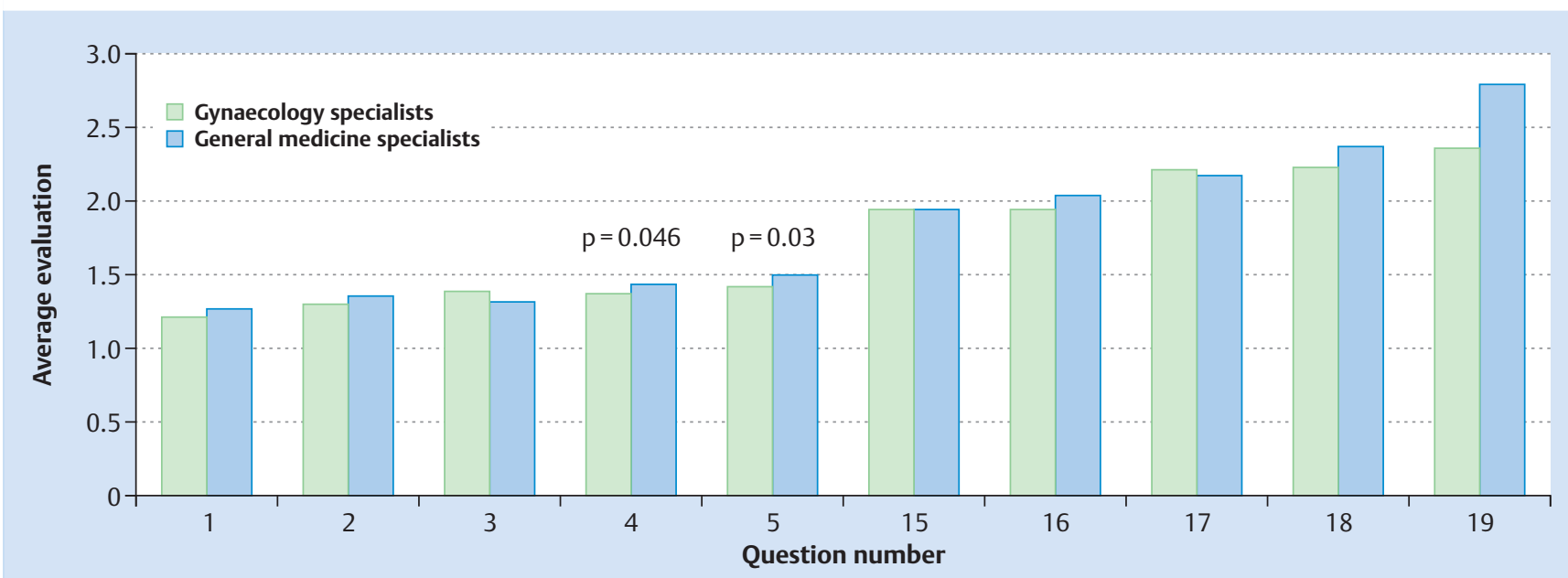

Fig. 4 The bar graphs represent the average scores of the gynaecology and the general medicine specialists for the questions 1-5 and 15-19.

Table 2 List of average scores for all questions arranged according to decreasing order of importance.

\begin{tabular}{|c|c|c|}
\hline $\begin{array}{l}\text { Ran- } \\
\text { king }\end{array}$ & Item & $\begin{array}{l}\text { Average } \\
\text { value }\end{array}$ \\
\hline 1 & competence and quality of the hospital & 1.25 \\
\hline 2 & surgical spectrum/surgical standards & 1.32 \\
\hline 3 & range of services/available therapies & 1.36 \\
\hline 4 & reachability of a competent person/physician & 1.4 \\
\hline 5 & range of prenatal diagnostics & 1.46 \\
\hline 6 & medical-technical equipment in the hospital & 1.47 \\
\hline 7 & $\begin{array}{l}\text { experience of patients or, respectively, } \\
\text { patient satisfaction }\end{array}$ & 1.5 \\
\hline 8 & standards of care or, respectively, nursing & 1.58 \\
\hline 9 & communication or, respectively, physicians' reports & 1.6 \\
\hline 10 & quick assignment of appointments & 1.77 \\
\hline 11 & reputation of the hospital or, respectively, its leaders & 1.85 \\
\hline 12 & $\begin{array}{l}\text { contact maintenance by physicians employed by the } \\
\text { hospital }\end{array}$ & 1.85 \\
\hline 13 & patient's wish for a specific hospital & 1.88 \\
\hline 14 & reachability of the hospital (hotline, homepage) & 1.93 \\
\hline 15 & number of operations performed & 1.94 \\
\hline 16 & previous cooperation & 1.97 \\
\hline 17 & regional proximity & 2.2 \\
\hline 18 & $\begin{array}{l}\text { attendance of hospital physicians at special further } \\
\text { training events }\end{array}$ & 2.29 \\
\hline 19 & $\begin{array}{l}\text { reputation or, respectively, personal contacts with } \\
\text { the colleagues }\end{array}$ & 2.49 \\
\hline
\end{tabular}

For the patient-related aspects, the experience and satisfaction of patients with the medical facility, in particular, are of major relevance. In contrast, the quick assignment of appointments, the regional proximity or the special wishes of the patient are considered to be less relevant.

Aspects such as public reputation of an individual person or a hospital, the personal relationships with colleagues, special further training events or previous cooperation play a subordinate role as factors influencing a referral.

Thus, it is apparent that the referral of patients by practice-based specialists is primarily based on the medical competence of the respective hospital.
On examining the differences in the evaluation of questions between the 2 largest groups of specialists significant differences were seen concerning the questions 4 and 5 . The reachability of a competent partner and, even more so, the availability of prenatal diagnostics were considered to be significantly more important by gynaecologists than by specialists in general medicine. In contrast, for the 3 most highly judged questions, namely, quality and competence, surgical spectrum and the range of diagnostic and therapeutic services of a hospital, no significant differences were seen between the two large specialist groups.

Also for the 5 questions with the lowest evaluations, there were no significant differences between the specialist groups.

The relatively high return of more than $50 \%$ of the sent out questionnaires is probably due on the one hand to the 3 different possibilities for returning them. On the other hand there was the opportunity to express criticism about the cooperation with hospitals. This was provided by the last question for which own comments could be freely given. Some participants used this chance to list critical points and provide suggestions for improvements. Although Spießl et al. [9] determined the prompt transmission of physicians' reports to be an important criterion for an ideal cooperation, among our collective these documents were considered to of only moderate importance. As Leonard et al. could demonstrate [10], not only the communication by means of physicians' reports but also direct personal contacts play an important role in the relationship between practice-based physicians and those employed by hospitals. This was also observed in our study where the reachability of a competent partner was considered to be the 4 th most important criterion for the referral of a patient. On the other hand, the lack of feedback by hospital physicians was a frequently seen reason for dissatisfaction among practicebased doctors [11].

One aspect for an improvement in cooperation is provided by the question concerning the previous cooperation between practicebased and hospital physicians. This question was assigned only a low importance and thus landed in position 16 . The result of this is that, in the case of a previous non-optimal cooperation, future communications can be improved by expeditious and easily realisable measures. This could be achieved with little effort, for example, by establishment of a hospital telephone with which a competent partner can be quickly reached. 
Besides further training events for physicians or, respectively, informative events for patients, the internet presence of a hospital as well as publically accessible quality reports could be applied to provide outsiders with a survey of the range of services or, respectively, the specialisation of a clinical facility.

In such cases, quality reports should provide information about the diagnostic and therapeutic capabilities of the individual hospitals. However, quality reports do not reflect the specific characteristics of a hospital [12]. These quality reports play only a subordinate role for the referral of a patient to a particular hospital [13]. From the patient's point of view, quality reports do not inform about the important and interesting aspects [14]. They thus help only in a very limited way to provide the practice-based specialist or the patient with an overview of the medical specifications of a hospital.

The role of the practice-based specialist in the recommendation of a patient for or against a specific clinic needs to be considered in a more differentiated manner. Thus, Lux et al. demonstrated varying influences of the patient by the practice-based specialist in dependence on the existing disease [15]. Accordingly, for $55.4 \%$ of women with a referral to a breast centre, the practicebased specialist was the deciding factor for the choice of a particular hospital. In contrast for gynaecological and obstetric patients, their own previous experiences with the respective centre were the most important factor for presenting to a particular hospital [15].

In spite of the high number of completed questionnaires, it must still be considered that the results could possibly be biased by the fact that the questionnaire was perhaps mainly answered by colleagues who were particularly satisfied with their previously experienced cooperation. On the other hand, it may have been that the questionnaires were mainly answered by specialists who considered their previous cooperation to be badly in need of improvement and so took this opportunity to express their criticisms of hospitals.

Furthermore, one must consider that this study was carried by a gynaecological hospital, i.e., a facility in which the surgical portion of its diagnostic and therapeutic spectrum is very large. To what extent the present evaluation of the individual questions can be transferred to facilities with a large proportion of conservative measures in their diagnostic and therapeutic spectra has not been studied. A further factor that was not considered is whether a different patient collective, by inclusion of male patients as is the case in other specialist hospitals, would have led to a different result.

In contrast to the weaknesses of the study listed here, the high response rate of the dispatched questionnaires and also the interdisciplinary participation of specialists in widely differing fields have to be taken into account.

As a conclusion from this study, it is apparent that a wide and modern range of services in combination with easily reachable competent partners are the deciding factors for the referral of (female) patients by practice-based specialists to a specific hospital. Contact between the hospitals and practice-based specialists can be achieved, for example, by practically-oriented further training events. Furthermore, the internet presence of a hospital and, al- beit only to a minor degree, quality reports serve as additional sources of information.

Surprisingly, even after an intensive literature search, only few references can be found concerning the deciding factors for practice-based specialists when referring their (female) patients to a specific hospital. Most of the publications on this topic come from the specialties neurology and psychiatry. Although the cooperation between practice-based specialists and clinical facilities represents the crux for an optimal and trouble-free care of patients, this topic has only been rarely examined scientifically, thus further investigations on this subject are needed.

\section{Conflict of Interest \\ $\nabla$}

None.

\section{Affiliations}

${ }^{1}$ Klinik für Frauenheilkunde, Geburtshilfe und Reproduktionsmedizin,

Universitätsklinikum des Saarlandes, Homburg/Saar

2 Praxis Prof. Dr. Dhom \& Partner, Ludwigshafen

3 Zentrum für Palliativmedizin und Kinderschmerztherapie,

Universitätsklinikum des Saarlandes, Homburg

${ }^{4}$ Frauenklinik, Klinikum Krefeld, Krefeld

\section{References}

1 Spießl H, Semsch I, Cording C et al. Erwartungen niedergelassener Nervenärzte und Allgemeinärzte an die psychiatrische Klinik. Nervenarzt 2001; 72: 190-195

2 Deutsche Gesellschaft für Psychiatrie, Psychotherapie und Nervenheilkunde (DGPPN). Die Behandlung psychischer Erkrankungen in Deutschland. Berlin, Heidelberg, New York: Springer; 1997

3 Craven MA, Cohen M, Campbell D et al. Mental health practices of Ontario family physicians: a study using qualitative methodology. Can J Psychiatry 1997; 42: 943-949

4 Fähndrich E, Kruckenberg P, Pontzen W. Befragung von Psychiatern in Praxis und Klinik zur gegenwärtigen Versorgungssituation psychiatrischer Patienten in Berlin. Psychiat Prax 1976; 3: 214-221

5 Kates $N$. Psychiatric consultation in the family physician's office. Advantages and hidden benefits. Gen Hosp Psychiatry 1988; 10: 431-437

6 Thomas RV, Corney RH. Working with community mental health professionals: a survey among general practitioners. Br J Gen Pract 1993; 43: 417-421

7 Robertson NC. Variation in referral pattern to the psychiatric services by general practitioners. Psychol Med 1979; 9: 355-364

8 Gottlieb JF, Olfson M. Current referral practices of mental health care providers. Hosp Community Psychiatry 1987; 38: 1171-1181

9 Spießl H, Cording C. Der Arztbrief - Visitenkarte der psychiatrischen Klinik? Psychiat Prax 2000; 27: 239-242

10 Leonard I, Babbs C, Creed F. Psychiatric referrals within the hospital the communication process. J R Soc Med 1990; 83: 241-244

11 Bennett $C$. The Worcester development project: general practitioner satisfaction with a new community psychiatric service. J R Coll Gen Pract 1989; 39: 106-109

12 Solomayer EF, Rody A, Wallwiener $D$ et al. Assessment of university gynecology clinics based on quality reports. Geburtsh Frauenheilk 2013; 73: 705-712

13 Hermeling P, Geraedts M. Kennen und nutzen Ärzte den strukturierten Qualitätsbericht? Gesundheitswesen 2012

14 Seidel G, Haase I, Walle E et al. Verständlichkeit und Nutzen von Qualitätsberichten Rehabilitation aus Sicht der Nutzer. Gesundheitswesen 2009; 71: A254

15 Lux MP, Fasching PA, Schrauder M et al. The era of centers: the influence of establishing specialized centers on patients' choice of hospital. Arch Gynecol Obstet 2011; 283: 559-568 